\title{
Evaluation of Anti-inflammatory and Regenerative Efficiency of Naringin and Naringenin in Degenerated Human Nucleus Pulposus Cells: Biological and Molecular Modeling Studies
}

\author{
Vijaya Madhuri Devraj ${ }^{1,2,}$, Satish Kumar Vemuri ${ }^{1, *}$, Rajkiran Reddy Banala ${ }^{1,}$, \\ Shravan Kumar Gunda ${ }^{3}$, Gurava Reddy $\mathrm{AV}^{1}$, Subbaiah GPV ${ }^{1,2}$ \\ ${ }^{1}$ Sunshine Medical Academy of Research and Training, Sunshine Hospitals, Secunderabad, India \\ ${ }^{2}$ Department of Spine Surgery, Star Hospitals, Hyderabad, India \\ ${ }^{3}$ Bioinformatics Division, Prof. G. Ram Reddy Centre for Distance Education, Osmania University, Hyderabad, India
}

\begin{abstract}
Study Design: Development of an in vitro model for assessing the anti-inflammatory efficacies of naringin (Nar) and naringenin (NG). Purpose: To evaluate the efficacy of natural flavonoids as therapeutic drugs against anti-inflammatory processes in the nucleus pulposus (NP) cells using in-vitro and in-silico methods.

Overview of Literature: Intervertebral disc (IVD) disease is a common cause of low back pain. Chronic inflammation and degeneration play a significant role in its etiopathology. Thus, a better understanding of anti-inflammatory agents and their role in IVD degeneration and pro-inflammatory cytokines expression is necessary for pain management and regeneration in IVD.

Methods: We performed primary cell culture of NP cells; immunocytochemistry; gene expression studies of cytokines, metalloproteases, extracellular proteins, and apoptotic markers using quantitative polymerase chain reaction and reverse transcription-polymerase chain reaction (RT-PCR); cytotoxicity assay (MTT); and molecular docking studies using AutoDock 4.2 software (Molecular Graphics Laboratory, La Jolla, CA, USA) to confirm the binding mode of proteins and synthesized complexes. We calculated the mean \pm standard deviation values and performed analysis of variance and $t$-test using SPSS ver. 17.0 (SPSS Inc., Chicago, IL, USA).

Results: Molecular docking showed that both Nar and NG bind to the selected genes of interest. Semi-quantitative RT-PCR analysis reveals differential gene expression of collagen (COL)9A1, COL9A2, COL9A3, COL11A2, COMT (catechol-0-methyltransferase), and THBS2 (thrombospondin 2); up regulation of ACAN (aggrecan), COL1A1, COL11A1, interleukin (IL)6, IL10, IL18R1, IL18RAP, metalloprotease (MMP)2, MMP3, MMP9, ADAMTS5 (a disintegrin and metalloproteinase with thrombospondin motifs 5), IGF1R (insulin-like growth factor type 1 receptor), SPARC (secreted protein acidic and cysteine rich), PARK2 (parkin), VDR (vitamin D receptor), and BCL2 (B-cell lymphoma 2); down regulation of IL1A, CASP3 (caspase 3), and nine genes with predetermined concentrations of Nar and NG.

Conclusions: The present study evaluated the anti-inflammatory and regenerative efficiencies of Nar and NG in degenerated human NP cells. Altered gene expressions of cytokines, metalloproteases, extracellular proteins, apoptotic genes were dose responsive. The molecular docking (in silico) studies showed effective binding of these native ligands (Nar and NG) with genes identified as potent inhibitors of inflammation. Thus, these natural flavonoids could serve as anti-inflammatory agents in the treatment of low back pain and sciatica.
\end{abstract}

Keywords: Intervertebral disc degeneration; Flavonoids; Inflammation; Nucleus pulposus; Naringin and naringenin

Received Mar 9, 2019; Revised Apr 10, 2019; Accepted Apr 13, 2019

Corresponding author: Subbaiah GPV

Sunshine Medical Academy of Research and Training, Sunshine Hospitals, PG Road, Secunderabad 500003, Telangana, India;

Department of Spine Surgery, Star Hospitals, Road no 10, Banjara Hills, Hyderabad-500034, Telangana, India

Tel: +91-40-44550000, Fax: +91-40-27890091, E-mail: drgpvsubbaiahgoli@gmail.com

${ }^{*}$ These authors contributed equally to this work. 


\section{Introduction}

Intervertebral disc degeneration (IVDD) is a common cause of lower back pain. IVDD is a complex and multifactorial disease owing to the involvement of genetic and environmental factors in its etiology. Genetic analyses have confirmed the involvement of varied genes in the etiology of IVDD and the role of single nucleotide polymorphisms in genes, such as vitamin D receptor 1 (VDR1) [1], collagen IX alleles [2,3], metalloprotease-3 (MMP-3) [4], aggrecan (ACAN) [5], transforming growth factor-b (TGFb) [6], and interleukin (IL)-1 [7] are implicated in various studies.

The structural instability of disk is mainly due to the diminished production of proteoglycans in the extracellular matrix and over expression of pro-inflammatory genes and other pathological mediators [8-10]. Current treatments available for treating degenerative disk diseases are medication, physiotherapy, and surgery that do not ensure regeneration; thus, scientists worldwide have been attempting to identify strategies that involve the use of natural extracts or phytomolecules that have the potential to control IVDD and help in the regeneration of the intervertebral disc (IVD) [11]. There are several natural compounds, such as resveratrol $(3,5,4$ '-trihydroxytransstilbene), a plant phenolic compound found in the skin of grapes, blueberries, raspberries, simvastatin, atorvastatin, lovastatin, Rhizoma Drynariae, naringin (Nar), etc. that have the therapeutic potential for IVD repair. This effect is attributable to their anti-inflammatory and anti-oxidant properties that in turn enhance the proliferation of nucleus pulposus (NP) cells and downregulate the effects of tumor necrosis factor- $\beta$ and MMP3 gene expression, while elevating BMP-2 (bone morphogenetic protein-2), SRYbox transcription factor 6 (SOX6), ACAN, and type II collagen protein production in NP cells in vitro, suggesting that they provide beneficial effects in IVDD treatment [12-14].

Nar and naringenin (NG) are natural flavonoids found in citrus fruits, particularly grape fruit $[15,16]$. These flavonoids occur as glycosides bound to sugars and constitute about $50 \%-80 \%$ of all flavanoids [17]. NG, the aglycone of NAR [18] is hydrolyzed to aglycones by enterobacteria in the large bowel before being absorbed into the gastrointestinal tract [19]. It is also evident that these flavonoids are found excessively in citrus fruit herb. Rhizoma drynariae is a Chinese herbal plant that has the potential to perform bone healing and repair; further, it is clinically effective in relieving lower back pain symptoms [20] and most back, neck, and radicular pains. Despite their promise as therapeutic agents for IVDD repair, these molecules have not yet been applied clinically in isolation or combination therapies.

Nar is a citrus flavonoid commonly found in the pericarp of citrus fruits $[17,20]$. Numerous studies have reported the bioactivities of Nar and its potential for treating diseases. It appears to be useful in improving cardiovascular health and has potential anticancer effects [21]. However, it is only in recent times that the health benefits of Nar and NG on disk have received much attention.

This study was designed to evaluate the regenerative and anti-inflammatory efficiency of known flavonoids Nar and NG in vitro. NP cells were isolated from the explant disk tissue and treated with different concentrations of Nar and NG individually and in combination. Our findings reveal promising effects of flavonoids in treating IVDD. However, further studies are needed before performing any clinical trials.

\section{Materials and Methods}

Nar $\left(\mathrm{C}_{27} \mathrm{H}_{32} \mathrm{O}_{14}\right.$, Cat\#71162, Lot\# BCBQ1754) and NG $\left(\mathrm{C}_{15} \mathrm{H}_{12} \mathrm{O}_{5}\right.$, Cat\#N5893, Lot\# BCBR3619V) were purchased from Sigma-Aldrich (St. Louis, MO, USA). The purity of the compounds was $\geq 95 \%$ (high-performance liquid chromatography). Nar and NG were reconstituted in dimethyl sulfoxide (DMSO, Sigma-Aldrich) to prepare a stock solution of $2 \mathrm{mg} / \mathrm{mL}$. Dulbecco's modified eagle's medium/nutrient mixture F-12 Ham (DMEM/F12, 1:1 mixture), $10 \%$ fetal bovine serum (FBS), $0.1 \%$ collagenase type $\mathrm{I}$, antibiotic antimycotic solution $100 \times \mathrm{L}$ with 10,000 units penicillin, $100 \mathrm{mg}$ streptomycin and $25 \mu \mathrm{g}$ amphotericin B per $1 \mathrm{~mL}$ in $0.9 \%$ saline, $0.25 \%$ trypsinethylenediaminetetraacetic acid, centrifuge tubes (Tarsons cat\# 546041), $100 \mu \mathrm{m}$ Nylon Mesh (Himedia, Mumbai, India; reference TCP183), and all other chemicals and reagents were analytical/culture grade reagents purchased from Himedia and Sigma-Aldrich.

\section{Culture and characterization of human nucleus pulp- osus cells}

Disk tissues were collected from disk degenerative disease patients undergoing fusion and discectomy surgeries. This 
study was approved by the Institutional Ethical Committee (approval no., SS/2015/IEC127). The tissues were immediately collected in $20 \mathrm{~mL}$ saline supplemented with antibiotics solution and transported to the laboratory at $4^{\circ} \mathrm{C}$. All the procedures were conducted in a sterile environment. Tissues were washed with phosphate-buffered saline (PBS) solution repeatedly; thereafter, the NP cells were separated by slicing the disc tissue into $1 \mathrm{~mm}^{3}$ segments in a moist environment and digested with $0.1 \%$ collagenase type I at $37^{\circ} \mathrm{C}$ for 4 hours with intermittent shaking at 30-minute intervals. The reaction was then stopped with FBS. The digested mixture was then filtered through a sterile $100-\mu \mathrm{m}$ nylon mesh and centrifuged at $1,500 \mathrm{rpm}$ for 5 minutes to collect the cell pellet. The cells were washed in PBS solution repeatedly and re-suspended in DMEM F12 medium containing 10\% FBS and antibiotics (prostate-specific antigen) and seeded with cell concentration density of $1 \times 10^{5} / \mathrm{mL}$ into a $75-\mathrm{cm}^{2}$ flask. The cells were maintained in culture flasks at $37^{\circ} \mathrm{C}$ in $5 \% \mathrm{CO}_{2}$ atmosphere, and the culture media was changed 2-3 times a week. Flow cytometry was performed for characterization of the NP cells using CD 24 cell surface markers. On completion of characterization, the NP cells were used for further experimentation at passage $3[19,20]$.

\section{Treatment with naringin and naringenin}

Cultured NP cells $\left(5 \times 10^{4} / \mathrm{mL}\right)$ were seeded in three 12well cell culture plates for up to 72 hours before experimentation. Various concentrations $(5,10,20,50$, and $100 \mu \mathrm{g} / \mathrm{mL}$ ) of Nar and NG were added to the respective group wells individually and in 1:1, 1:2, and 2:1 combinations and control cells without any drug. The NP cells were cultured for 48 hours before harvest for RNA extraction [19].

\section{Immunocytochemistry of nucleus pulposus cells}

Randomly selected pellets were cultured on a cover slip. Once they attained required confluency, they were fixed with $100 \%$ ethanol for 20 minutes, immunostained with primary monoclonal antibodies against collagen II and SOX6, and were incubated overnight in the dark at $4^{\circ} \mathrm{C}$. Thereafter, they were counter-stained with fluorescent secondary antibody tagged to Alexa Fluor 488 for 1 hour and observed under a confocal microscope (Leica Biosystem SPE) $[19,20]$.

\section{Cell viability assay or MTT assay}

Normal cells, that is, the HEK cell lines were plated in 96well plates. Cells were treated with vehicle control or different doses of Nar and NG, and with combinations for 36 hours. We selected 10- $\mu$ g dose with 1:1, 1:2, and 2:1 ratio in combination therapy to avoid unwanted cytotoxicity in normal cells. After 36 hours, cell viability was analyzed using the MTT assay as per the published protocol, and absorbance was recorded at $475 \mathrm{~nm}$ with reference to $660 \mathrm{~nm}$ [22].

\section{Labeling mitochondria with MitoTracker Dye}

Stock solution was prepared by dissolving the lyophilized MitoTrackerR product in high-quality, anhydrous DMSO to a final concentration of $1 \mathrm{mM}$. The reduced rosamine MitoTrackerR probes (M7511) are sensitive to oxidation and are thus protected from the light. Staining solution was prepared by diluting $1 \mathrm{mM}$ MitoTrackerR stock solution to a final working concentration of $25-500 \mathrm{nM}$ in appropriate buffer or growth factor for staining cells that are to be fixed and permeabilized.

Cells were grown on cover slips inside a petri dish filled with the DMEM-F12 culture medium with $10 \%$ FBS. Once we attained preferred confluency, the complete media was replaced with pre-warmed $\left(37^{\circ} \mathrm{C}\right)$ media containing staining solution (i.e., MitoTrackerR probe) and incubated for 15-45 minutes in 5\% $\mathrm{CO}_{2}$ incubator. After 45 minutes of incubation, the staining solution was replaced with fresh pre-warmed media containing $3.7 \%$ formaldehyde and left at $37^{\circ} \mathrm{C}$ for 15 minutes. After fixation, the cells were rinsed several times with $1 \times$ PBS. The fixed cells were permeabilized by incubating in buffer-containing detergent $0.02 \%$ Triton X-100 for 10 minutes and then washed with $1 \times$ PBS. The cells were then visualized under a fluorescence microscope [23].

\section{Total RNA isolation, cDNA synthesis, and polymerase chain reaction (quantitative polymerase chain reac- tion and quantitative reverse transcription-polymerase chain reaction)}

After 48 hours, the NP cells were harvested with trypsinization, and total RNA was isolated using a Nucleopore Mini Kit (Genetix Biotech, New Delhi, India) from all 14 samples. Final RNA was eluted in $60-\mu \mathrm{L}$ RNase free water. The concentration of RNA was determined from 
Table 1. List of hypothetical genes involved in intervertebral disc disease

\begin{tabular}{|c|c|c|c|c|c|}
\hline No. & Genes & Gene name & Sequence $\left(5^{\prime}>-3^{\prime}\right)$ & $\begin{array}{l}\text { Temperature } \\
\left({ }^{\circ} \mathrm{C}\right)\end{array}$ & Functions \\
\hline \multirow[t]{2}{*}{1} & ACAN & Aggrecan & ССССТGCTATTTCATCGACCС & 64.5 & Resist compressive loads on tissue \\
\hline & & & GACACACGGCTCCACTTGAT & 62.5 & \\
\hline \multirow[t]{2}{*}{2} & ADAMTS5 & $\begin{array}{l}\text { A disintegrin and metalloproteinase } \\
\text { with thrombospondin motifs } 5\end{array}$ & GAACATCGACCAACTCTACTCCG & 64.6 & $\begin{array}{l}\text { Pathogenesis of human osteoarthri- } \\
\text { tis }\end{array}$ \\
\hline & & & CAATGCCCACCGAACCATCT & 62.5 & \\
\hline \multirow[t]{2}{*}{3} & BCL2 & B-cell lymphoma 2 & GGTGGGGTCATGTGTGTGG & 64.5 & Pro-apoptotic, anti-apoptotic \\
\hline & & & CGGTTCAGGTACTCAGTCATCC & 64.5 & \\
\hline \multirow[t]{2}{*}{4} & CASP3 & Caspase 3 & CATGGAAGCGAATCAATGGACT & 60.8 & Apoptosis \\
\hline & & & CTGTACCAGACCGAGATGTCA & 62.6 & \\
\hline \multirow[t]{2}{*}{5} & CASPg & Caspase 9 & CTCAGACCAGAGATTCGCAAAC & 62.7 & Apoptosis \\
\hline & & & GCATTTCСССТСАААСТСТСАА & 60.8 & \\
\hline \multirow[t]{2}{*}{6} & COL1A1 & Collagen I alpha 1 & GAGGGCCAAGACGAAGACATC & 64.5 & Rigidity and elasticity \\
\hline & & & CAGATCACGTCATCGCACAAC & 62.6 & \\
\hline \multirow[t]{2}{*}{7} & COL9A1 & Collagen IX alpha 1 & GGCAGTAGAGGAGAATTAGGACC & 64.6 & Delay onset of osteoarthritis \\
\hline & & & GTTCACCGACTACACCCCTG & 64.5 & \\
\hline \multirow[t]{2}{*}{8} & COL9A2 & Collagen IX alpha 2 & CTCGCTCTGGCGCAGATTAG & 64.5 & Cartilage and bone ossification \\
\hline & & & GCCCATTGTCACCGTCGAT & 62.3 & \\
\hline \multirow[t]{2}{*}{9} & COL9A3 & Collagen IX alpha 3 & GTGGATGGTCTGACTGGACG & 64.5 & Cartilage and bone ossification \\
\hline & & & GGGCAGATACTTGGGCACTG & 64.5 & \\
\hline \multirow[t]{2}{*}{10} & COL11A1 & Collagen XI alpha 1 & TAACATCGCTGACGGGAAGTG & 62.6 & Ossification, prevent disc bulging \\
\hline & & & CCGTGATTCCATTGGTATCAACA & 61.0 & \\
\hline \multirow[t]{2}{*}{11} & COL11A2 & Collagen XI alpha 2 & TCTTTGGTGCCCGTATTCTGG & 62.6 & Cartilage ossification \\
\hline & & & TGGGGTTCCTGATTTTGTGGC & 62.6 & \\
\hline \multirow[t]{2}{*}{12} & COMT & Catechol-0-methyltransferase & GAAGGGGACAGTGCTACTGG & 64.5 & $\begin{array}{l}\text { Inactivation of the catecholamine } \\
\text { neurotransmitters }\end{array}$ \\
\hline & & & CAGGAACGATTGGTAGTGTGTG & 62.7 & \\
\hline \multirow[t]{2}{*}{13} & IGF1R & $\begin{array}{l}\text { Insulin-like growth factor type } 1 \\
\text { receptor }\end{array}$ & AGGATATTGGGCTTTACAACCTG & 61.0 & Hypertrophy of muscle and tissue \\
\hline & & & GAGGTAACAGAGGTCAGCATTTT & 61.0 & \\
\hline \multirow[t]{2}{*}{14} & IL1A & Interleukin 1a & AGATGCCTGAGATACCCAAAACC & 62.8 & Inflammatory cytokine \\
\hline & & & CCAAGCACACCCAGTAGTCT & 62.5 & \\
\hline \multirow[t]{2}{*}{15} & IL6 & Interleukin 6 & АСTCACСTCTTCAGAACGAATTG & 61.0 & $\begin{array}{l}\text { Pro-inflammatory cytokine } \\
\text { Anti-inflammatory myokine }\end{array}$ \\
\hline & & & CCATCTTTGGAAGGTTCAGGTTG & 62.8 & \\
\hline \multirow[t]{2}{*}{16} & IL10 & Interleukin 10 & GACTTTAAGGGTTACCTGGGTTG & 62.8 & Anti-inflammatory cytokine \\
\hline & & & TCACATGCGCCTTGATGTCTG & 62.6 & \\
\hline \multirow[t]{2}{*}{17} & IL18R1 & Interleukin 18 receptor 1 & СCTTGACCCTTTGGGTGCTTA & 62.6 & $\begin{array}{l}\text { Pro-inflammatory } \\
\text { Interleukin-18-mediated signaling } \\
\text { pathway }\end{array}$ \\
\hline & & & CTCATGTGCAAGTGAACACGA & 60.6 & \\
\hline \multirow[t]{2}{*}{18} & IL18RAP & $\begin{array}{l}\text { Interleukin } 18 \text { receptor accessory } \\
\text { protein }\end{array}$ & АCCTGCCCTTCATGGGTAGTA & 62.6 & Cell-mediated immunity \\
\hline & & & CCCCTGGGGTCAAAAAGTGA & 62.5 & \\
\hline
\end{tabular}


Table 1. Continued

\begin{tabular}{|c|c|c|c|c|c|}
\hline No. & Genes & Gene name & Sequence $\left(5^{\prime}>-3^{\prime}\right)$ & $\begin{array}{l}\text { Temperature } \\
\qquad\left({ }^{\circ} \mathrm{C}\right)\end{array}$ & Functions \\
\hline \multirow[t]{2}{*}{19} & MMP2 & Matrix metalloproteinase 2 & GATACCCCTTTGACGGTAAGGA & 62.7 & Degradation of the disc matrix \\
\hline & & & ССTTCTCCCAAGGTCCATAGC & 64.5 & \\
\hline \multirow[t]{2}{*}{20} & MMP3 & Matrix metalloproteinase 3 & CGGTTCCGCCTGTCTCAAG & 64.5 & Breakdown of extracellular matrix \\
\hline & & & CGCCAAAAGTGCCTGTCTT & 60.2 & \\
\hline \multirow[t]{2}{*}{21} & MMPg & Matrix metalloproteinase 9 & GGGACGCAGACATCGTCATC & 64.5 & $\begin{array}{l}\text { Degradation of the extracellular } \\
\text { matrix }\end{array}$ \\
\hline & & & TCGTCATCGTCGAAATGGGC & 62.5 & \\
\hline \multirow[t]{2}{*}{22} & PARK2 & Parkin & GTGTTTGTCAGGTTCAACTCCA & 60.8 & Targeting of proteins for degradation \\
\hline & & & GAAAATCACACGCAACTGGTC & 60.6 & \\
\hline \multirow[t]{2}{*}{23} & SPARC & $\begin{array}{l}\text { Secreted protein acidic and cysteine } \\
\text { rich }\end{array}$ & CCСATTGGCGAGTTTGAGAAG & 62.6 & $\begin{array}{l}\text { Mineralization and promoting min- } \\
\text { eral crystal formation }\end{array}$ \\
\hline & & & CAAGGCCCGATGTAGTCCA & 62.3 & \\
\hline \multirow[t]{2}{*}{24} & THBS2 & Thrombospondin & ATAGACAGCTTCGCTCTGGAC & 62.6 & Cell adhesion and migration \\
\hline & & & САААССССТGAAGTGACTCTC & 62.6 & \\
\hline \multirow[t]{2}{*}{25} & VDR & Vitamin D receptor & TCTCCAATCTGGATCTGAGTGAA & 61.0 & $\begin{array}{l}\text { Normal bone mineralization and } \\
\text { remodeling }\end{array}$ \\
\hline & & & GGATGCTGTAACTGACCAGGT & 62.6 & Resist compressive loads on tissue \\
\hline
\end{tabular}

the optical density of the sample measured at $260 \mathrm{~nm}$ using nanodrop. The extracted RNA samples were analyzed for the expression of 25 genes: COL9A1, COL9A2, COL9A3, COL11A2, catechol-O-methyltransferase (COMT), THBS2 (thrombospondin 2), ACAN, COL1A1, COL11A1, 1L6, IL10, IL18R1, IL18RAP, MMP2, MMP3, MMP9, ADAMTS5 (a disintegrin and metalloproteinase with thrombospondin motifs 5), insulin-like growth factor type 1 receptor (IGF1R), secreted protein acidic and cysteine rich (SPARC), parkin (PARK2), VDR, B-cell lymphoma 2 (BCL2), IL1A, CASP3, CASP9, and glyceraldehyde 3-phosphate dehydrogenase (GAPDH) as a housekeeping gene. cDNA synthesis was conducted using a Verso cDNA Synthesis Kit (Thermo Fischer Scientific, Waltham, MA, USA), and the template DNA was used for gene-specific polymerase chain reaction (PCR, SimpliAmp Thermal Cycler, Applied Biosystems; Thermo Fischer Scientific) and reverse transcription-polymerase chain reaction (RT-PCR) (QuantStudio 5, Applied Biosystems; Thermo Fischer Scientific). PCR and RT-PCR reactions were performed as per the manufacturer's instructions. Primers used in this study were designed using the online "Primer3" program (http://bioinfo.ut.ee/primer3-0.4.0/ primer3/); the details of the primers are listed in Table 1.

All PCR products were visualized on $1.5 \%$ agarose gel with $0.5 \mathrm{mg} / \mathrm{mL}$ ethidium bromide. Photographs were taken using the gel documentation system (E Gel Imager; Life Technologies, Carlsbad, CA, USA) [22].

\section{Molecular docking studies}

Molecular docking studies were performed to explain the binding mode of proteins and ligands. All the compounds were docked using the AutoDock 4.2 software (Molecular Graphics Laboratory, La Jolla, CA, USA). All the molecules were docked individually in AutoDock 4.2 [24-26]. The modeled three-dimensional structure of all the proteins was imported to AutoDock 4.2 and structurally optimized by adding hydrogens to the protein allocated with kollman charges. After adding the hydrogens, the model was saved in the PDBQT format; thereafter, ligands were prepared by optimizing the torsion angles and saved in the PDBQT format. The potential binding site for all the proteins were selected by using PDBSUM (http://www.ebi. ac.uk/pdbsum) [24-27]. A grid was generated to identify the xyz coordinates around the binding site of the proteins individually. Lamarckian genetic algorithm (LGA) was selected for freezing docking and default parameters used in AutoDock 4.2. 
Day 0

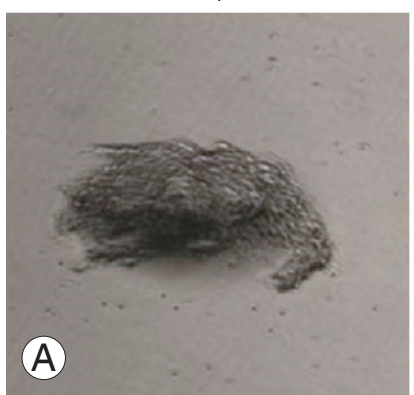

Day 7

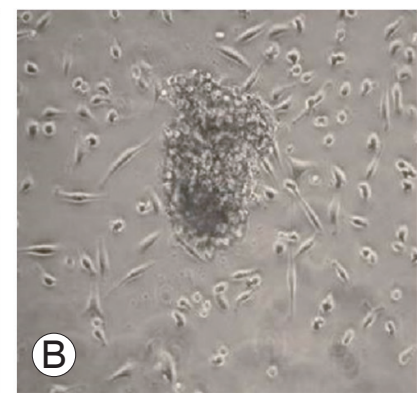

Day 21

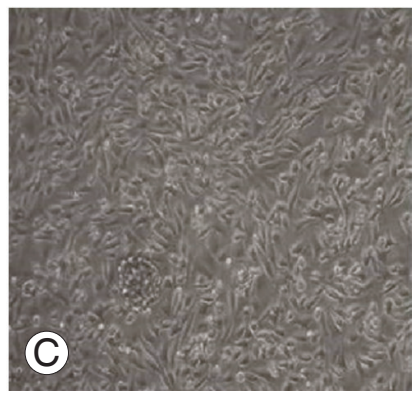

Fig. 1. Culture of human nucleus pulposus cells from degenerated intervertebral disc. (A) Day 0: explant from the degenerated disk; (B) day 7: cells propagating out from the explants and; (C) day 21: culture flask became fully confluent. The cells were polygonal in shape like chondrocytes.
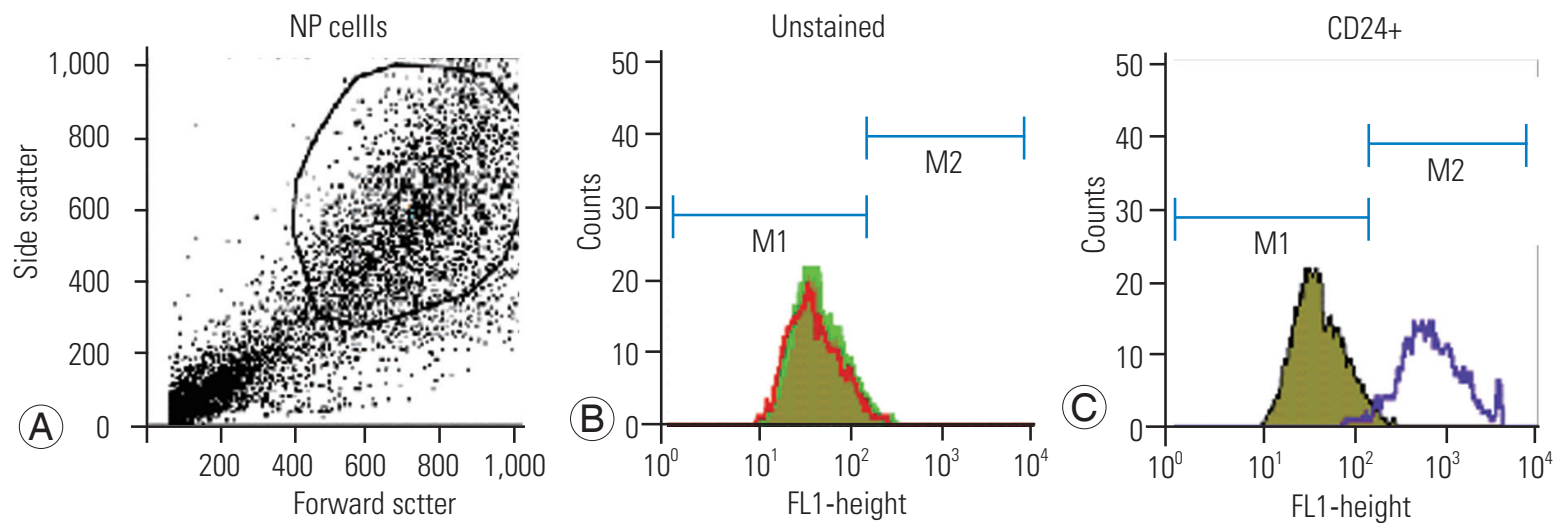

Fig. 2. (A-C) Characterization of NP cells using CD24 marker on flow cytometer analysis. NP, nucleus pulposus.

\section{Statistical analyses}

All the individual results are expressed as mean \pm standard deviation values. The mean values of the grouped results were tested using two-way analysis of variance (ANOVA) test, evaluated with the statistical packages SPSS ver. 17.0 (SPSS Inc., Chicago, IL, USA). A p-value $<0.05$ was accepted as statistically significant.

\section{Informed consent}

This study was approved by the Institutional Ethical Board of the Sunshine Hospital and Research Centre (approval no., SS/2015/IEC127). Written informed consent was sought after providing complete study description to the subjects.

\section{Results}

\section{Culture of the human nucleus pulposus cells}

NP cells were successfully isolated from the degenerated IVD from the lumbar spine and were further cultured for
$\mathrm{P}_{0}-\mathrm{P}_{3}$ generations, propagated, expanded, and characterized after the third passage (Figs. 1, 2).

\section{Treatment with naringin and naringenin}

Cultured NP cells $\left(5 \times 10^{4}\right.$ cells $\left./ \mathrm{mL}\right)$ were seeded in 12 -well plates and incubated for 72 hours before the experiment. Different concentrations of Nar and NG (5, 10, 20, 50, and $100 \mu \mathrm{g} / \mathrm{mL}$ ) were added to wells in duplicates, and combinations of both were added in 1:1 (10:10 and 20:20 $\mu \mathrm{g} / \mathrm{mL})$, $1: 2(10: 20 \mu \mathrm{g} / \mathrm{mL})$, and $2: 1(20: 10 \mu \mathrm{g} / \mathrm{mL})$ ratios to the respective group wells in duplicate (Fig. 3). In comparison with the individual treatments, the combinatorial treatments of Nar-NG (1:2 and 2:1 ratios) did not show much significance; however, the dosages of Nar, NG (10-50 $\mu \mathrm{g} /$ $\mathrm{mL}$ ) individually and in combination (1:1 ratio), resulted in a significant increase as confirmed on post-PCR gel images at particular concentrations. However, no cytotoxicity was observed at $100 \mu \mathrm{g} / \mathrm{mL}$, and the concentration of 20 $\mu \mathrm{g} / \mathrm{mL}$ Nar and NG appeared most effective and was found to be the optimum dose for promoting cell proliferation. 


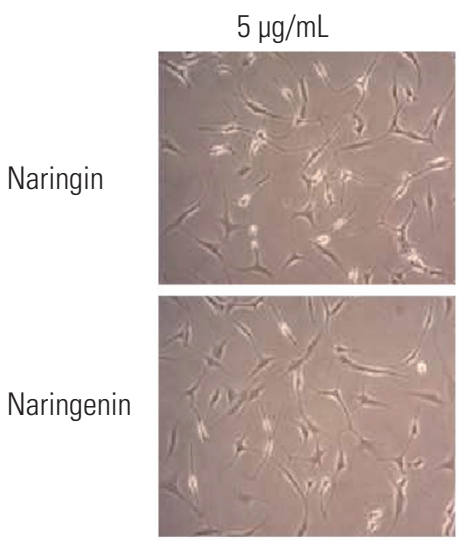

$1: 1$

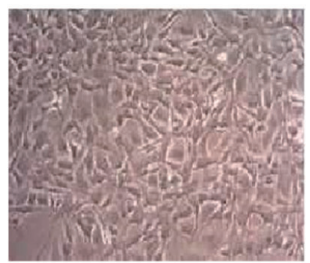

$10 \mu \mathrm{g} / \mathrm{mL}$
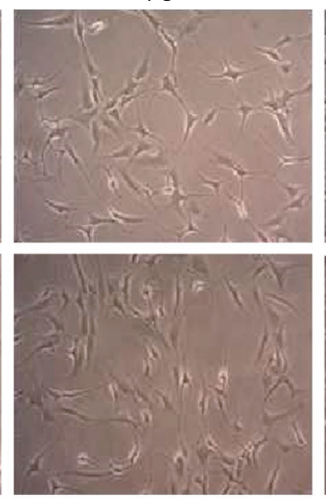

$1: 2$

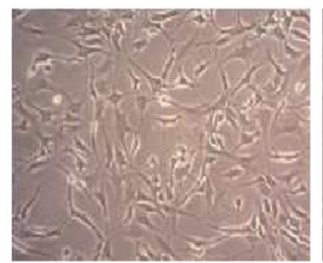

$20 \mu \mathrm{g} / \mathrm{mL}$
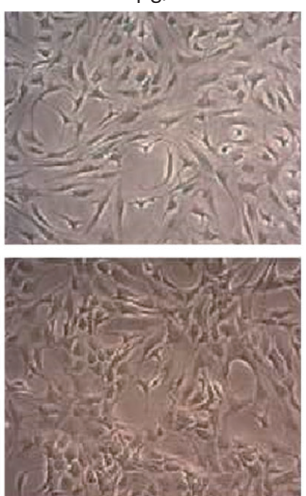

2:1

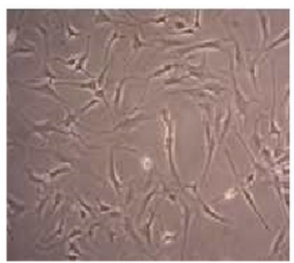

$50 \mu \mathrm{g} / \mathrm{mL}$
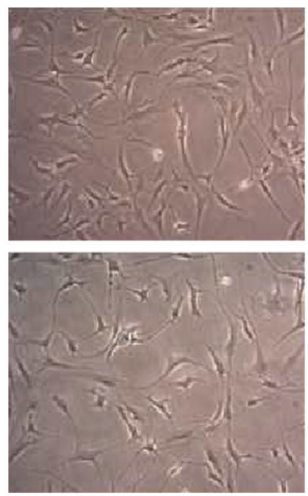

Control

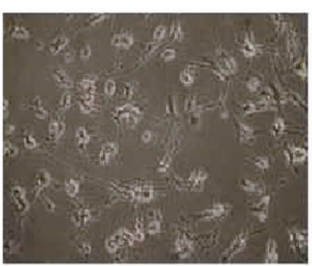

Fig. 3. Effect of naringin and naringenin as well as their combination on NP cells at various concentrations, including 5, 10, 20, 50, and 100 $\mu \mathrm{g} / \mathrm{mL}$ and the combination of naringin and naringenin in the following three ratios: 1:1, 1:2, and 2:1 compared to control. We examined the growth enhancement effect of naringin and naringenin on NP cells. NP, nucleus pulposus.

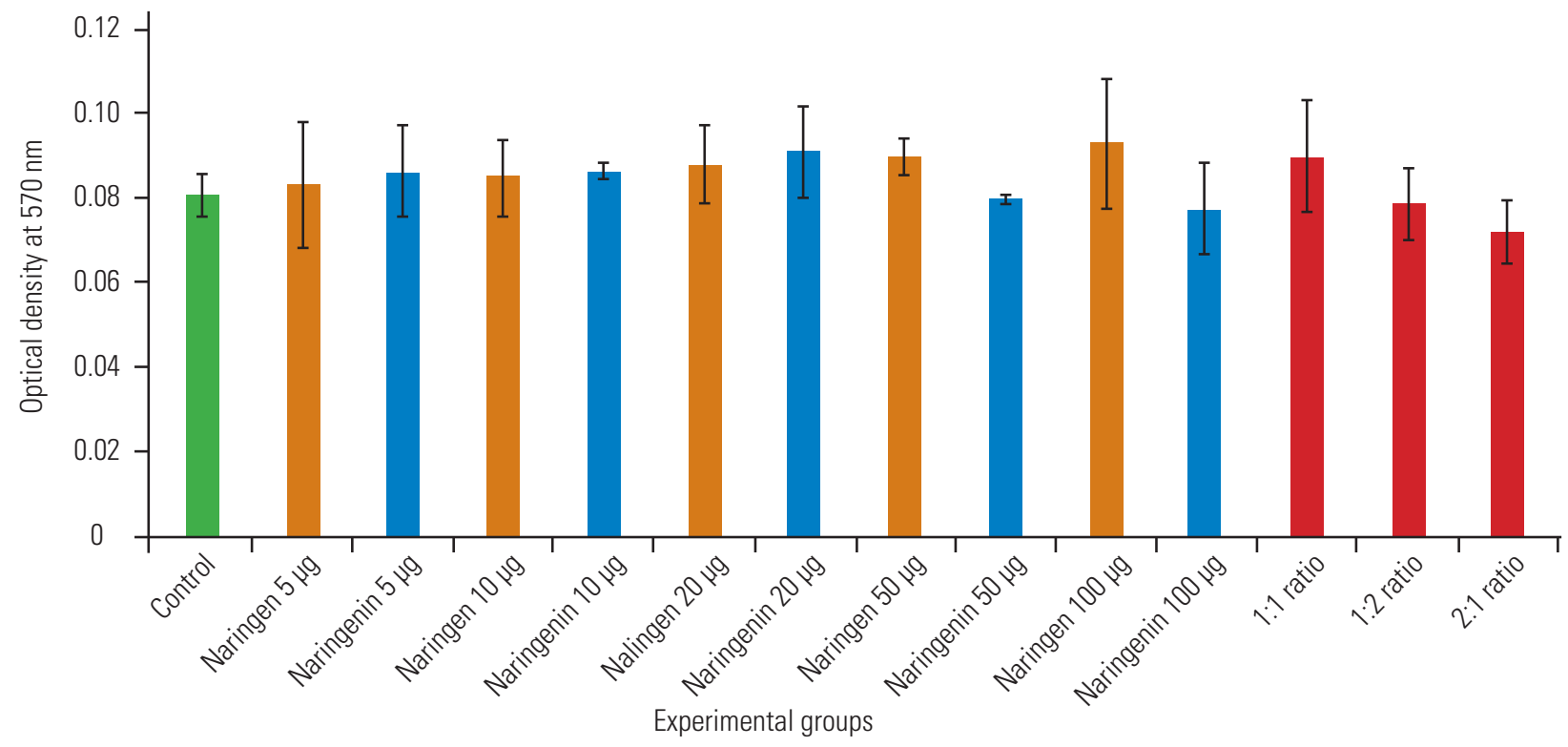

Fig. 4. MTT assay for assessing the cytotoxicity of individual and combinatorial flavonoid treatments in normal cell line (HEK 293).

\section{Cytotoxicity studies-MTT assay}

We performed an MTT assay study for assessing the proliferation efficiency in the HEK-293 cell line in the presence of Nar and NG individually and in combination after 36 hours of exposure (Fig. 4). However, the results of the MTT assay suggest that Nar or NG do not induce any cytotoxicity in the HEK-293 (normal) cell line, and the cells were proliferating normally when treated with similar dosages under our study conditions.

\section{Immunocytochemistry for nucleus pulposus cells}

After treatment with $20 \mu \mathrm{g} / \mathrm{mL}$ Nar and NG and their combination in a 1:1 ratio, the NP cells were immunostained with primary monoclonal antibodies collagen II 

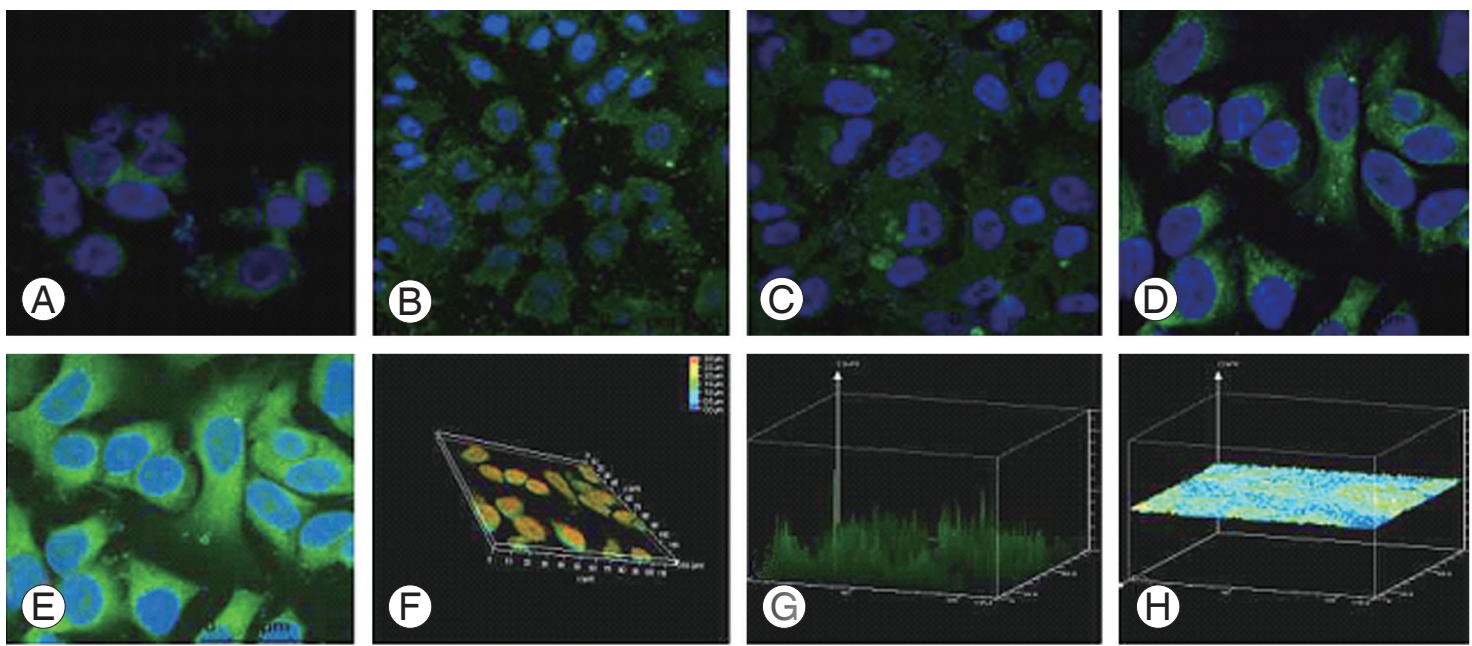

Fig. 5. Immunocytochemistry of NP cells stained with type II collagen and SOX2 (SRY-box transcription factor 6) antibody counterstained with DAPI (4', 6-diamidino-2-phenylindole) nuclear stain visualized under confocal laser scanning microscope. (A) Untreated controls, (B) naringin $(20 \mu \mathrm{g} / \mathrm{mL})$, (C) naringenin $(20 \mu \mathrm{g} / \mathrm{mL})$, and (D) naringin+naringenin (1:1 ratio). Cross-section analyses along the flattened Np cells showing a width of cell fluorescent intensity histogram visualized using confocal microscopy. (E) Np cells after drug treatment, (F) depth coding, (G) histogram image, and (H) three-dimensional topographical image. NP, nucleus pulposus.

and SOX2 and were then counter-stained with fluorescent secondary antibody Alexa-488 mounted with DAPI (4', 6-diamidino-2-phenylindole) nuclear stain. It showed higher expression in the cells treated with Nar and NG compared than in the untreated control sample (Fig. 5).

\section{Labeling mitochondria with Mitotracker dye}

After treatment with Nar and NG, the cells were loaded with Mitotracker Green FM for mitochondria staining; representative images of mitochondrial morphology are shown in Fig. 6. Thus, mitochondrial morphological changes were analyzed with and without the drug. Mitochondria in control sample, expression was reduced under oxidative stress condition in cells, suggesting disruption and depolarization of mitochondria without drug whereas in drug-treated cells it showed over expression.

\section{Effect of naringin and naringenin on gene expression} assessed using reverse transcription-polymerase chain reaction

Real-time PCR followed by gel electrophoresis was used to assess the changes in the expression of 26 genes (i.e., ACAN, collagens, interleukins, MMP, ADAMTS, etc.) constituting the markers for disk and inflammation (Fig. 7). All the samples considered for RT-PCR had five concentra-
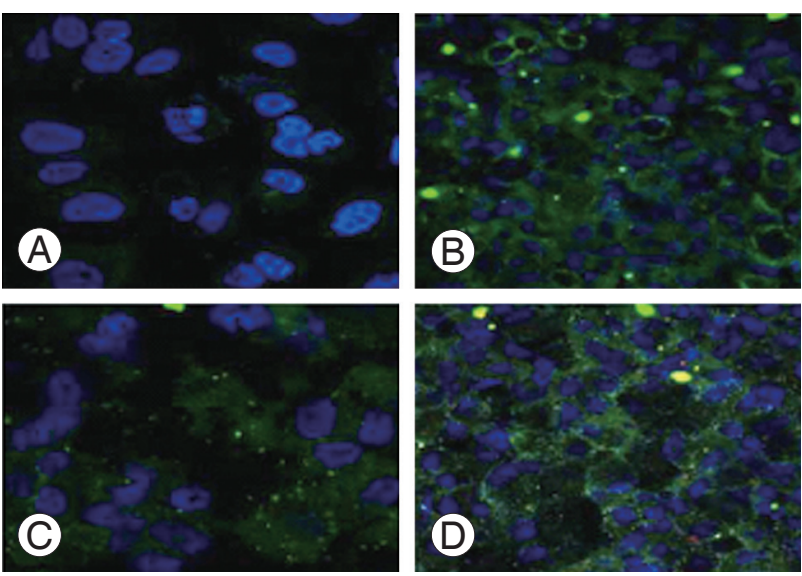

Fig. 6. Mitochondria stained with Mitotracker Green, showing mitochondria distribution using fluorescent microscope. (A) Control. (B) Naringin. (C) Naringenin. (D) Naringin+naringenin.

tions each of Nar and NG $(10,25,50,100$, and $200 \mu \mathrm{g} / \mathrm{mL})$ and were used in the ratios of 1:1, 1:2, and 2:1 of both Nar and NG as combination drugs. Cells that were not given any treatment were considered as controls. The subsequent section includes an overview of the genes studied and their expression (upregulation and downregulation) as mentioned in Table 2. Further, we observed changes in the gene expression of similar genes with different drug concentrations.

GAPDH was used as a housekeeping gene. The dosedependent Nar and NG increased the expression of discogenic regeneration markers, such as collagen and ACAN. 
CTRL N5 N10 N20 N50 N100 NA5NA10NA20 NA50 NA100 1:1 1:2 2:1

\begin{tabular}{|c|c|c|}
\hline GAPDH & $---------1----$ & CASP9 \\
\hline ACAN & $-----=-------$ & CASP3 \\
\hline ADAMTS5 & 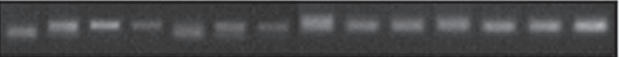 & MMP2 \\
\hline IGFR & 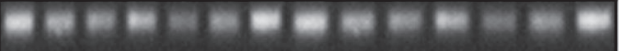 & MMP3 \\
\hline ILA & $\sin$ & MMP9 \\
\hline IL6 & 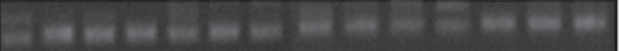 & COMT \\
\hline IL10 & 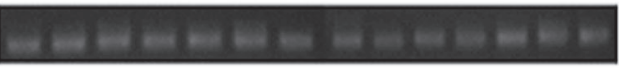 & SPARC \\
\hline COL1A1 & 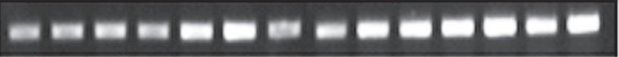 & THBS2 \\
\hline COL9A1 & 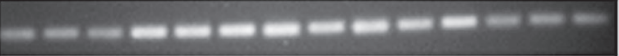 & IL18R \\
\hline COL9A2 & - & IL18RAP \\
\hline COL9A3 & 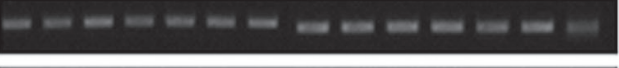 & BCL2 \\
\hline COL11A1 & 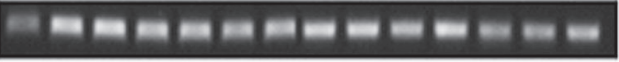 & PARK \\
\hline COL11A2 & 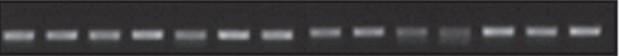 & VDR \\
\hline
\end{tabular}

CTRL N5 N10 N20 N50 N100 NA5NA10 NA20 NA50 NA100 1:1 1:2 2:1

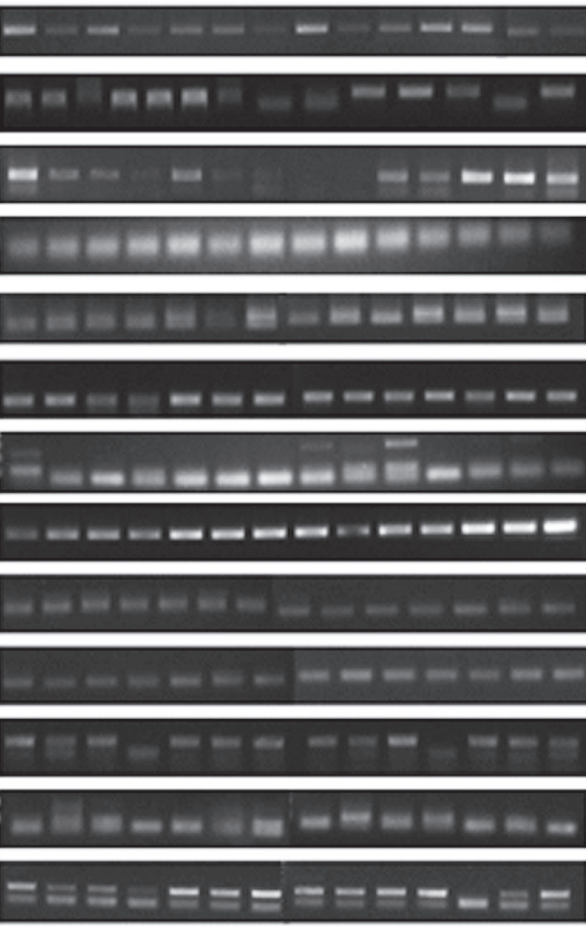

Fig. 7. Gene expression pattern of 25 genes with different concentration of drug using gel electrophoresis. GAPDH, glyceraldehyde 3-phosphate dehydrogenase; ACAN, aggrecan; ADAMTS5, a disintegrin and metalloproteinase with thrombospondin motifs 5; IGFR, insulin-like growth factor receptor; IL, interleukin; COL, collagen; CASP, caspase; MMP, matrix metalloproteinase; COMT, catechol0-methyltransferase; SPARC, secreted protein acidic and cysteine rich; THBS2, thrombospondin 2; BCL2, B-cell Iymphoma 2; PARK2, parkin; VDR, vitamin D receptor.

Maximal expression was observed at a concentration of 20 $\mu \mathrm{g} / \mathrm{mL}$, and the combination usage of $1: 2$ concentration showed dramatically increased gene expression. However, treatment with Nar and NG showed effectiveness toward minimal expression of inflammatory markers, such as interleukins, caspase, and MMPs (Fig. 7).

\section{Heat map effect}

Grouped double gradient heat map was done using twoway ANOVA. The table of rows and columns factor of untreated (control) and treated (drug) versus means of various genes (expression by RT-PCR) showed a $p$-value with statistical significance $(p=0.0033,0.0009)$. Fig. 8 shows the heat map of the grouped data (Fig. 8A) with two rows and 25 columns corresponding to 25 genes (treated and untreated) (Fig. 8B) 25 genes with respect to various dosages; smallest value coded in green show higher expression, and the largest values in red show lower expression.Twoway ANOVA showed a significant $p$-value for both, the row and column factors with $p$-value $<0.001$. Genes were expressed deferentially in the control and treated groups, showing either up regulation or down regulation for most genes, while other genes have shown a trend toward marginal or neutral expression levels.

\section{Molecular docking interactions of naringin and nar- ingenin}

Docking of NG and Nar compounds into the binding site of all the proteins was performed to estimate the binding affinity of the complex. It is a significant part of the structure-based drug design process. It is an open-source software for drug discovery and molecular docking. The structural interactions between Protein Data Bank (PDB) with two inhibitors were docked separately. Docking studies are commonly performed for predicting the binding affinities of proteins and the binding energies of their ligands. $\mathrm{X}, \mathrm{Y}$, and $\mathrm{Z}$ coordinates of all the PDB's were selected by using SPDBV (http://www.expasy.org/spdbv/). Autodock 4.2 uses binding free energy assessment to assign the best binding conformation.

A molecular docking study was performed by using AutoDock 4.2. In this docking process, the protein is set 
Trendline between treated and untreated group involving different genes

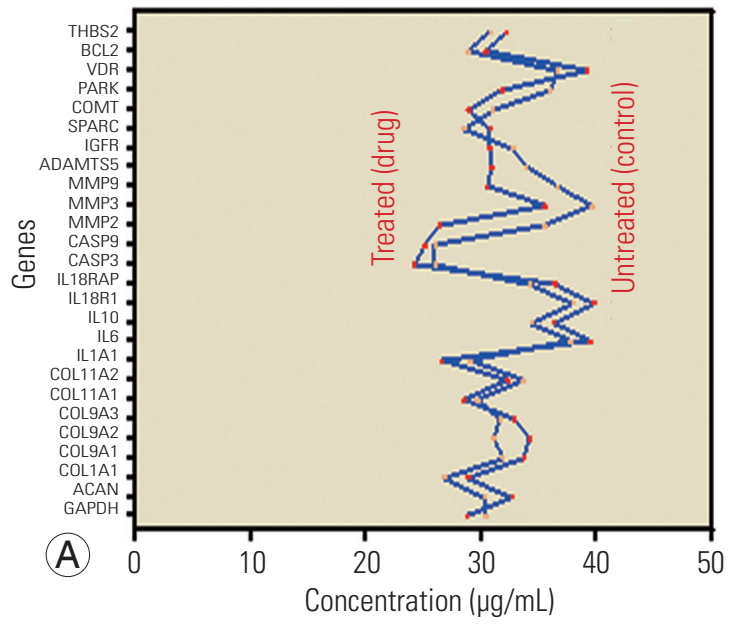

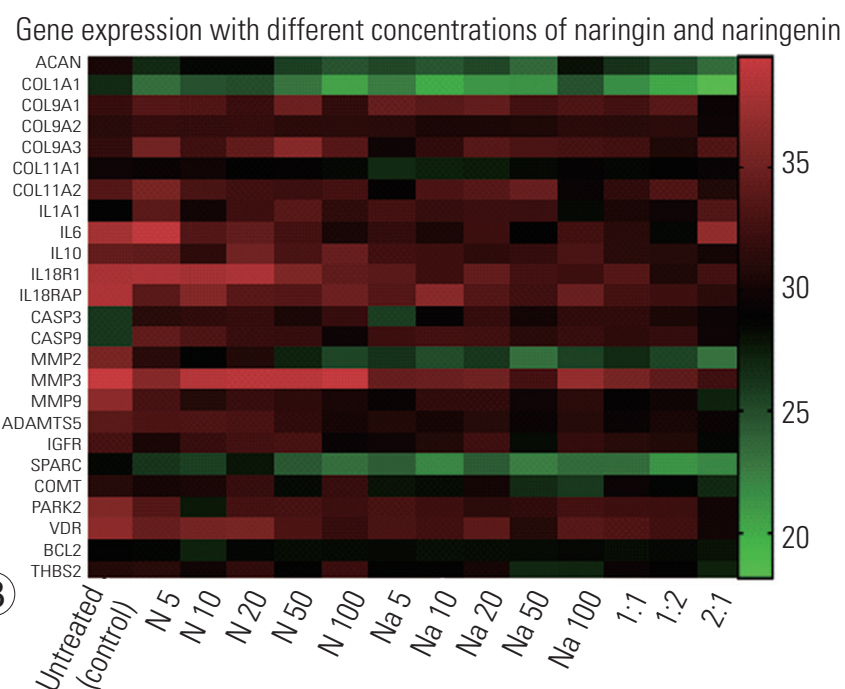

Fig. 8. (A) Trend line between the control and treated groups vs. that in different genes. Gene Expression of 25 discogenic genes involved in intervertebral disc. (B) Heat map effect between the control and treated group (different concentrations) vs. that in different genes. THBS2, thrombospondin 2; BCL2, B-cell lymphoma 2; VDR, vitamin D receptor; PARK2, parkin; COMT, catechol-0-methyltransferase; SPARC, secreted protein acidic and cysteine rich; IGFR, insulin-like growth factor receptor; ADAMTS5, a disintegrin and metalloproteinase with thrombospondin motifs 5; MMP, matrix metalloproteinase; CASP, caspase; IL, interleukin; COL, collagen; ACAN, aggrecan; GAPDH, glyceraldehyde 3-phosphate dehydrogenase.

as rigid and the ligand as flexible. AutoDock uses the LGA to search for the best conformation with reference to the minimum binding energy $(\mathrm{kcal} / \mathrm{mol})$ and hydrogen bond distance between the protein and the ligand.

Molecular docking is the most extensively used method for the calculation of protein-ligand interactions. It is an efficient method to predict the potential ligand interactions. In this study, the native ligands (NG and Nar) were identified as potent different cancer inhibitors. AutoDock 4.2 uses binding free energy assessment to assign the best binding conformation. Dockings of the NG and Nar compounds are summarized in Tables 2 and 3, respectively. Both the derivatives selected for molecular docking have some collective structural features. The comparison of free energies corresponding to the binding of title compounds with target protein reveals that maximum of the compounds interact with the receptor. Almost all molecules exhibited lower free energy values, indicating more thermodynamically favored interaction.

\section{Naringenin}

Molecular interaction between NG with different cancer targets, calculated the docking score. The protein was downloaded from RCSB (https://www.rcsb.org) for docking analysis. It was found that NG made Hydrogen bond with the amino acid residue Pro221 and Thr215 of PDB ID: 1D8M, a MMP3 target with binding energy of -8.56 $\mathrm{kcal} / \mathrm{mol}$. It also shows a hydrogen bond with Ala136 and Val117 with binding energy of $-7.97 \mathrm{kcal} / \mathrm{mol}$ a MMP2 protein.

Similarly, we docked with the following targets VDR, CASP9, COL1A1, COMT, ADAMTS5, MMP9, CASP3, PARK2, IGFR1R, IL18RAP, ACAN, IL181, IL6, IL10, SPARC, IL1A, and BCL2. Nar was docked against all these targets. Among these, MMP3, MMP2, VDR, CASP9, COL1A1, and COMT targets show the best binding energy of $>-7.0 \mathrm{kcal} / \mathrm{mol}$. Except BCL2, all the other targets showed good binding energy and interactions.

\section{Naringin}

Molecular interaction between Nar with different cancer targets, calculated the docking score. The protein was downloaded from PDB for docking analysis. Nar created a hydrogen bond with the amino acid residue Leu295, Asn297, and Asn293 of PDB ID: 2OJ9, an IGFR1R target with a binding energy of $-7.10 \mathrm{kcal} / \mathrm{mol}$. It also showed a hydrogen bond with Ala136 and Leu83 with a binding energy of $-7.09 \mathrm{kcal} / \mathrm{mol}$ a MMP2 (Table 2).

Similarly, we docked with the following targets: VDR, CASP9, COL1A1, COMT, ADAMTS5, MMP9, CASP3, PARK2, IGFR1R, IL18RAP, ACAN, IL181, IL6, IL10, SPARC, IL1A, and BCL2. Out of these targets IL10, IGFR1R, MMP2, IL18RAP, CASP9, MMP3, CASP3, MMP9, ADAMTS5, and ACAN only shows a binding 
Table 2. Molecular docking interactions of naringin with their binding energy

\begin{tabular}{|c|c|c|c|c|c|}
\hline Gene name & PDB ID & Interacting amino acids & Grid X-Y-Z coordinates & $\begin{array}{l}\text { Binding energy } \Delta \mathrm{G} \\
\text { (kcal/mol) }\end{array}$ & $\begin{array}{c}\text { Dissociation } \\
\text { constant }(\mathrm{kl})(\mu \mathrm{M})\end{array}$ \\
\hline IL10 & 2ILK & Lys117, Ser118, Lys119 & $22.601,40.659,43.545$ & -4.16 & 889.49 \\
\hline COL1A1 & 3EJH & Arg552, Lys554, Arg967 & $-23.600,17.974,-4.216$ & -3.15 & $4.89 \mathrm{mM}$ \\
\hline BCL2 & $4 \mathrm{AO} 3$ & Trp103, Asn151(2), Val101 & $-28.353,15.626,-21.45$ & -4.42 & 572.84 \\
\hline CASP3 & $2 \mathrm{C} 20$ & Asp2(2), Trp214, Asn208, Glu146 & $37.644,25.480,23.831$ & -5.65 & 72.16 \\
\hline CASPg & 2AR9 & - & $18.979,34.366,-14.505$ & -5.67 & 69.52 \\
\hline COMT & 3A7E & Asp44, Tyr200, Arg201 & $-20.385,14.881,13.606$ & 303.56 & - \\
\hline IGFR1R & $20 J 9$ & Leu295, Asn297, Asn293 & $1.028,-2.661,12.226$ & -7.1 & 6.2 \\
\hline IL1A & IIRA & Lys109(2), Lys111, Glu94 & $46.907,7.065,57.268$ & -3.75 & $1.78 \mathrm{mM}$ \\
\hline IL6 & $1 \mathrm{ALU}$ & Gly77, Ser76 & $-17.612,-13.109,7.459$ & -3.53 & $2.59 \mathrm{mM}$ \\
\hline IL18RAP & 3W04 & Glu32, Thr21, Glu22 & $-45.056,-2.620,-25.058$ & -5.95 & 43.53 \\
\hline IL181 & $4 \mathrm{R} 6 \mathrm{U}$ & His1030, Lys1120, Cys1029, Glu995 & $274.429,-35.631,115.918$ & -3.74 & $1.83 \mathrm{mM}$ \\
\hline MMP2 & $1 \mathrm{HOV}$ & Ala136, Leu83 & $7.840,20.181,15.297$ & -7.09 & 6.33 \\
\hline MMP3 & $4 \mathrm{D} 8 \mathrm{M}$ & Ala167(3) & $66.413,77.078,37.874$ & -5.67 & 69.5 \\
\hline MMPg & $1 \mathrm{GKD}$ & Asp410, Ala191, His411 & $6.214,47.409,-17.281$ & -5.42 & 107.12 \\
\hline PARK2 & $5 C 12$ & 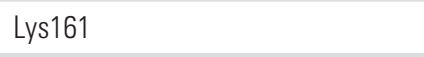 & $-21.821,23.775,18.419$ & -3.74 & $1.8 \mathrm{mM}$ \\
\hline SPARC & $2 \vee 53$ & Ile226(3), Leu266 & $12.436,30.887,29.607$ & -3.65 & 2.11 \\
\hline VDR & $5 G T 4$ & Lys240, GIn239 & $-9.061,-10.888,29.360$ & -3.87 & 1.45 \\
\hline ACAN & 4MD4 & Lys111, Glu88 & $26.646,30.740,-5.433$ & -5.07 & 191.53 \\
\hline ADAMTS5 & $3 H Y G$ & $\begin{array}{l}\text { Val384, Ala382, His420, Thr378, } \\
\text { Ser419 }\end{array}$ & $15.531,-1.503,1.836$ & -5.28 & 134.02 \\
\hline
\end{tabular}

PDB, Protein Data Bank; IL, interleukin; COL1A1, collagen I alpha 1; BCL2, B-cell lymphoma 2; CASP, caspase; COMT, catechol-0-methyltransferase; IGF1R, insulin-like growth factor type 1 receptor; MMP, matrix metalloproteinase; PARK2, parkin; SPARC, secreted protein acidic and cysteine rich; VDR, vitamin D receptor; ACAN, aggrecan; ADAMTS5, a disintegrin and metalloproteinase with thrombospondin motifs 5.

energy of -5.0 , and other targets showed less binding energy.

From the docking simulation, we observed free energy charge of binding for the protein-ligand complex. A possible explanation may be that the radiographical structure of the protein from crystals differs from that of the aqueous system. The total energy was calculated for both the compounds against different targets shown in the Tables 2 and 3. Therefore, it can be concluded that the interaction of Nar and NG with the corresponding targets is hydrophobic interactions in nature. Molecular docking indicated that the distance of hydrogen bonding between the ligand and the protein, respectively.

AutoDock 4.2 uses binding free energy assessment to assign the best binding conformation. Experimental activities and predicted values by LGA. Dockings of the Nar and NG compounds are summarized in Table 2 and Table 3 , respectively.

\section{Discussion}

The present study systematically studied the effects of Nar and NG on explant disk tissue and evaluated their potency in alleviating the disease condition by enhanced NP cells proliferation in the disk tissue. Further, the mechanisms of action of Nar and NG in IVDD were understood by the specific gene expression among variably considered genes for our research. Based on the above findings and our knowledge on Nar and NG as important natural drugs available, we decided to characterize the ratio of Nar/NG on NP cells regeneration in patients with IVDD.

Characterization of the NP cells was performed using flow cytometry (i.e., using CD24 marker). Immunocytochemistry studies were also performed where the NP cells were characterized subsequently using type II collagen and SOX2 antibody counter-stained with DAPI nuclear stain, showing higher expression in cells treated with Nar and NG than in untreated cells (Figs. 2, 5). Our results 
Table 3. Molecular docking interactions of naringenin with their binding energy

\begin{tabular}{|c|c|c|c|c|c|}
\hline Gene name & PDB ID & Interacting amino acids & Grid X-Y-Z coordinates & $\begin{array}{l}\text { Binding energy } \\
\Delta \mathrm{G} \text { (kcal/mol) }\end{array}$ & $\begin{array}{c}\text { Dissociation } \\
\text { constant }(\mathrm{kl})(\mu \mathrm{M})\end{array}$ \\
\hline IL10 & 2ILK & Arg110, Lys117 & $22.601,40.659,43.545$ & -5.14 & 171.8 \\
\hline COL1A1 & 3EJH & Tyr525, Leu963 & $-23.600,17.974,-4.216$ & -7.19 & 5.38 \\
\hline BCL2 & 4A03 & Asp150,Glu159 & $-28.353,15.626,-21.45$ & -4.44 & 553.93 \\
\hline CASP3 & $2 \mathrm{C} 20$ & Asn208, Trp214, Glu248, Asp2 & $37.644,25.480,23.831$ & -6.07 & 78.29 \\
\hline CASP9 & 2AR9 & - & $18.979,34.366,-14.505$ & -7.79 & 2.06 \\
\hline COMT & 3A7E & Arg201, Val42 & $-20.385,14.881,13.606$ & -7.16 & 5.63 \\
\hline IGFR1R & $20 J 9$ & His1030, Asn1028, Thr998 & $1.028,-2.661,12.226$ & -5.87 & 50.15 \\
\hline IL1A & IIRA & Leu35, GIn20 & $46.907,7.065,57.268$ & -5.05 & 72.15 \\
\hline IL6 & $1 \mathrm{ALU}$ & - & $-17.612,-13.109,7.459$ & -5.28 & 134.36 \\
\hline IL18RAP & 3W04 & Arg113, Glu122, Arg123 & $-45.056,-2.620,-25.058$ & -5.86 & 50.63 \\
\hline IL181 & $4 \mathrm{R} 6 \mathrm{U}$ & Gly252, Leu295 & $274.429,-35.631,115.918$ & -5.33 & 124.08 \\
\hline MMP2 & & Ala136, Val117 & $7.840,20.181,15.297$ & -7.97 & 1.45 \\
\hline MMP3 & $1 \mathrm{D} 8 \mathrm{M}$ & Pro221, Thr215 & $66.413,77.078,37.874$ & -8.56 & $535.28 \mathrm{nM}$ \\
\hline MMPg & $1 \mathrm{GKD}$ & Leu114, Asp410, Ala191 & $6.214,47.409,-17.281$ & -6.62 & 14.13 \\
\hline PARK2 & $5 \mathrm{C} 1 \mathrm{Z}$ & Arg163, Thr83, Val456 & $-21.821,23.775,18.419$ & -5.99 & 170.24 \\
\hline SPARC & $2 V 53$ & Lys282, Asp222, Asp267 & $12.436,30.887,29.607$ & -5.14 & 170.24 \\
\hline VDR & 5GT4 & Asp144, Ser278, Thr236 & $-9.061,-10.888,29.360$ & -7.80 & 1.91 \\
\hline ACAN & 4MD4 & - & $26.646,30.740,-5.433$ & -5.71 & 65.01 \\
\hline ADAMTS5 & $3 H Y G$ & Ala382, Ser315 & $15.531,-1.503,1.836$ & -6.71 & 12.08 \\
\hline
\end{tabular}

PDB, Protein Data Bank; IL, interleukin; COL1A1, collagen I alpha 1; BCL2, B-cell lymphoma 2; CASP, caspase; COMT, catechol-0-methyltransferase; IGF1R, insulin-like growth factor type 1 receptor; MMP, matrix metalloproteinase; PARK2, parkin; SPARC, secreted protein acidic and cysteine rich; VDR, vitamin D receptor; ACAN, aggrecan; ADAMTS5, a disintegrin and metalloproteinase with thrombospondin motifs 5.

showed that Nar and NG appear to enhance the proliferation of human NP cells in a dose-dependent manner independently (i.e., 5, 10, 20, 50, and $100 \mu \mathrm{g} / \mathrm{mL}$ ). All these concentrations showed varied effectiveness with the type of gene involved, with a majority being noticed as having beneficial effects. The concentration of $5 \mu \mathrm{g} / \mathrm{mL}$ was too low to show its effect in cells and that of $100 \mu \mathrm{g} / \mathrm{mL}$ was too high and caused cell apoptosis; thus, the optimum dosages of $10 \mu \mathrm{g} / \mathrm{mL}$ and $50 \mu \mathrm{g} / \mathrm{mL}$ had the highest influence on cell proliferation (Fig. 4).

Mitochondrial morphological changes were also analyzed with and without drug treatment. Mitochondrial expression in the control sample was reduced under oxidative stress conditions in the cells, suggesting disruption and depolarization of the mitochondria without drug; however, the mitochondria were over-expressed in the drug-treated cells (Fig. 6). Up regulation of discogenic markers and down regulation of inflammatory markers was noticed in the NP cells. We observed that treatment with these drugs effectively diminished the inflammatory

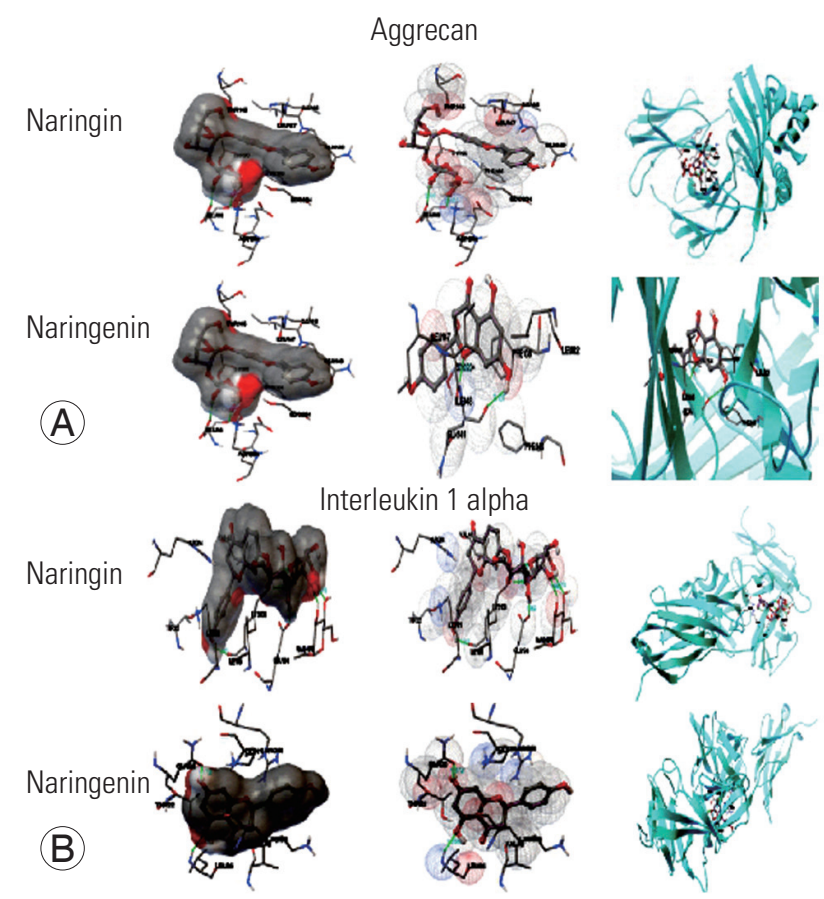

Fig. 9. (A, B) Molecular docking conformations of naringin and naringenin with aggrecan and interleukin 1 alpha. 


Proteins

Fig. 10. Molecular docking conformations among naringin, naringenin, and proteins. ACAN, aggrecan; ADAMTS5, a disintegrin and metalloproteinase with thrombospondin motifs 5; BCL, B-cell lymphoma; CASP, caspase; COL, collagen; COMT, catechol-0-methyltransferase; IGF1R, insulin-like growth factor type 1 receptor; IL, interleukin; MMP, matrix metalloproteinase; PARK2, parkin; VDR, vitamin D receptor. (Continued to the next page).

IL10

Fig. 10. Continued.

cytokine expression individually and in combination. Further, the expression of elevated disk markers was obvious after Nar and NG treatment, indicating repair and regeneration of the NP cells in the disk tissue (Fig. 7). 
RT-PCR results showed that the genes responsible for pro-inflammation, such as interleukins, caspases, and MMPs, were down regulated, while those with functions of discogenesis, bone repair, and collagen formation (such as collagen and ACAN) were well expressed, suggesting an overall beneficial effect of these flavonoids (Fig. 8A, B).

We further studied molecular docking to confirm the binding efficiency and dissociation constants for both Nar and NG. This is important because computational and bioinformatics tools are the most extensively used methods for calculating protein-ligand interactions [26]. This is an efficient method to predict potential ligand interactions. In this study, the native ligands (Nar and NG) were identified as potent inhibitors of inflammation. Both the derivatives selected for molecular docking have some collective structural features. The comparison of free energies corresponding to the binding of title compounds with the target protein reveals that most of the compounds interact with the receptor. Almost all the molecules exhibited lower free energy values, indicating more thermodynamically favored interactions (Figs. 9, 10).

\section{Conclusions}

Our study revealed that the use of these flavonoids to inhibit the function of inflammatory cytokines using virtual screening is an important consideration. In contrast, inhibitory constant energy and energy binding levels of certain disc markers suggested a repair mechanism to regenerate NP cells.

The present study clearly shows that citrus flavonoids are useful for improvement of inter vertebral disc properties. Further, it is noted that elevated discogenic markers expression was evident after Nar and NG treatment that indicates repair and regeneration of the NP cells in the disc tissue. We studied the expression profile of various genes using RT-PCR that revealed deferentially up-regulated and down-regulated genes. The binding efficiency of these genes to flavonoids, such as Nar and NG, were confirmed in molecular docking studies that identified them as having potent anti-inflammatory properties that improved their clinical treatment efficacy. Thus, they should be recommended for use in the treatment of patients with lumbar problems.

\section{Conflict of Interest}

No potential conflict of interest relevant to this article was reported.

\section{Acknowledgments}

We wish to extend our sincere thanks to Dr Adarsh Reddy A and Dr Kushal $\mathrm{H}$ from Sunshine Medical Academy of Research and Training, Sunshine Hospitals and Star Hospitals for their continuous support. Special thanks to Dr Paul Marx for his support during the study.

\section{References}

1. Li Y, Zhu J, Gao C, Peng B. Vitamin D receptor (VDR) genetic polymorphisms associated with intervertebral disc degeneration. J Genet Genomics 2015;42:135-40.

2. Annunen S, Paassilta P, Lohiniva J, et al. An allele of COL9A2 associated with intervertebral disc disease. Science 1999;285:409-12.

3. Seki S, Kawaguchi Y, Mori M, et al. Association study of COL9A2 with lumbar disc disease in the Japanese population. J Hum Genet 2006;51:1063-7.

4. Ito S, Kimura K, Haneda M, Ishida Y, Sawada M, Isobe $\mathrm{K}$. Induction of matrix metalloproteinases (MMP3, MMP12 and MMP13) expression in the microglia by amyloid-beta stimulation via the PI3K/Akt pathway. Exp Gerontol 2007;42:532-7.

5. Mashayekhi F, Shafiee G, Kazemi M, Dolati P. Lumbar disk degeneration disease and aggrecan gene polymorphism in northern Iran. Biochem Genet 2010;48:684-9.

6. Jin $H$, Shen J, Wang B, Wang M, Shu B, Chen D. TGF- $\beta$ signaling plays an essential role in the growth and maintenance of intervertebral disc tissue. FEBS Lett 2011;585:1209-15.

7. Karppinen J, Solovieva S, Luoma K, Raininko R, Leino-Arjas P, Riihimaki H. Modic changes and interleukin 1 gene locus polymorphisms in occupational cohort of middle-aged men. Eur Spine J 2009;18:1963-70.

8. Schwarzer AC, Aprill CN, Derby R, Fortin J, Kine G, Bogduk N. The prevalence and clinical features of internal disc disruption in patients with chronic low back pain. Spine (Phila Pa 1976) 1995;20:1878-83.

9. Battie MC, Videman T. Lumbar disc degeneration: 
epidemiology and genetics. J Bone Joint Surg Am 2006;88 Suppl 2:3-9.

10. Anderson DG, Tannoury C. Molecular pathogenic factors in symptomatic disc degeneration. Spine J 2005;5(6 Suppl):260S-266S.

11. Le Maitre CL, Pockert A, Buttle DJ, Freemont AJ, Hoyland JA. Matrix synthesis and degradation in human intervertebral disc degeneration. Biochem Soc Trans 2007;35(Pt 4):652-5.

12. Erlund I, Meririnne E, Alfthan G, Aro A. Plasma kinetics and urinary excretion of the flavanones naringenin and hesperetin in humans after ingestion of orange juice and grapefruit juice. J Nutr 2001;131:235-41.

13. Kanno S, Tomizawa A, Hiura T, et al. Inhibitory effects of naringenin on tumor growth in human cancer cell lines and sarcoma S-180-implanted mice. Biol Pharm Bull 2005;28:527-30.

14. Chanet A, Milenkovic D, Deval C, et al. Naringin, the major grapefruit flavonoid, specifically affects atherosclerosis development in diet-induced hypercholesterolemia in mice. J Nutr Biochem 2012;23:469-77.

15. Kuntz S, Wenzel U, Daniel H. Comparative analysis of the effects of flavonoids on proliferation, cytotoxicity, and apoptosis in human colon cancer cell lines. Eur J Nutr 1999;38:133-42.

16. Duan YJ, Mu G, Kang Z, Zhang G. Treatment of intervertebral disc herniation patients 115 with self made low back pain capsule. Clin J Tradit Chin Med 2005;1:1901.

17. Lu Y, Zhang C, Bucheli P, Wei D. Citrus flavonoids in fruit and traditional Chinese medicinal food ingredients in China. Plant Foods Hum Nutr 2006;61:57-65.

18. Benavente-Garcia O, Castillo J. Update on uses and properties of citrus flavonoids: new findings in anticancer, cardiovascular, and anti-inflammatory activity. J Agric Food Chem 2008;56:6185-205.
19. Kluba T, Niemeyer T, Gaissmaier C, Grunder T. Human anulus fibrosis and nucleus pulposus cells of the intervertebral disc: effect of degeneration and culture system on cell phenotype. Spine (Phila Pa 1976) 2005;30:2743-8.

20. Li N, Whitaker C, Xu Z, Heggeness M, Yang SY. Therapeutic effects of naringin on degenerative human nucleus pulposus cells for discogenic low back pain. Spine J 2016;16:1231-7.

21. Baskari S, Govatati S, Madhuri V, et al. Influence of autocrine growth hormone on NF- $\mathrm{kB}$ activation leading to epithelial-mesenchymal transition of mammary carcinoma. Tumour Biol 2017;39:1010428317719121.

22. Vemuri SK, Banala RR, Subbaiah GP, Srivastava SK, Reddy AG, Malarvili T. Anti-cancer potential of a mix of natural extracts of turmeric, ginger and garlic: a cell-based study. Egypt J Basic Appl Sci 2017;4:332-44.

23. Keij JF, Bell-Prince C, Steinkamp JA. Staining of mitochondrial membranes with 10-nonyl acridine orange, MitoFluor Green, and MitoTracker Green is affected by mitochondrial membrane potential altering drugs. Cytometry 2000;39:203-10.

24. Laskowski RA. PDBsum new things. Nucleic Acids Res 2009;37(Database issue):D355-9.

25. Morris GM, Huey R, Lindstrom W, et al. AutoDock4 and AutoDockTools4: automated docking with selective receptor flexibility. J Comput Chem 2009;30:2785-91.

26. Osguthorpe DJ, Sherman W, Hagler AT. Generation of receptor structural ensembles for virtual screening using binding site shape analysis and clustering. Chem Biol Drug Des 2012;80:182-93.

27. Goodsell DS, Olson AJ. Automated docking of substrates to proteins by simulated annealing. Proteins 1990;8:195-202. 